\title{
Size- and shape-dependent clinical and mycological efficacy of silver nanoparticles on dandruff
}

\author{
This article was published in the following Dove Press journal: \\ International Journal of Nanomedicine \\ 6 January 2016 \\ Number of times this article has been viewed
}

\author{
Mohammad F Anwar' \\ Deepak Yadav ${ }^{2}$ \\ Swati Jain ${ }^{3}$ \\ Sumeet Kapoor ${ }^{4}$ \\ Shweta Rastogi ${ }^{5}$ \\ Indu Arora ${ }^{6}$ \\ Mohammed Samim' \\ 'Department of Chemistry, Faculty of \\ Science, ${ }^{2}$ Faculty of Medicine, Jamia \\ Hamdard University, New Delhi, \\ ${ }^{3}$ Amity Institute of Nanotechnology, \\ Amity University, Noida, Uttar \\ Pradesh, ${ }^{4}$ Centre for Biomedical \\ Engineering, Indian Institute of \\ Technology, Delhi, ${ }^{5}$ Department \\ of Chemistry, Hans Raj College, \\ ${ }^{6}$ Department of Biomedical Sciences, \\ Rajguru College of Applied Sciences \\ for Women, University of Delhi, Delhi, \\ India
}

Correspondence: Mohammed Samim Department of Chemistry, Jamia Hamdard University, Hamdard Nagar, New Delhi I 10062, India

Tel +9 I II 26059688 ext 5557

Fax +9| || 26059663

Emailshamim_chem@yahoo.co.in

\begin{abstract}
Dandruff is a prominent scalp problem caused by the growth of fungus Malassezia furfur, potentially cascading into dermal inflammation, itching, and tissue damage. The present work outlines a detailed analysis of the treatment of scalp infection using silver nanomaterials (Ag NMs), and focuses on biocidal activity owing to manipulation of size, shape, and structure. Monodisperse silver spherical nanoparticles (NPs) and nanorods (NRs) were synthesized by chemical routes that were characterized using analytical and spectroscopic techniques. Ag NMs demonstrated enhanced biocidal tendencies compared to market available drugs, itracanozole and ketoconazole, showing greater zones of inhibition. The obtained $20 \mathrm{~nm}$ and $50 \mathrm{~nm}$ spherical-shaped NPs and $50 \mathrm{~nm}$ NRs showed concentration-, size-, and shape-dependent antifungal activity, with $20 \mathrm{~nm}$ spherical-shaped NPs exhibiting excellent potency. Minimum inhibitory concentration for $20 \mathrm{~nm}$ was lowest at $0.2 \mathrm{mg} / \mathrm{mL}$ in comparison to $0.3 \mathrm{mg} / \mathrm{mL}$ for NRs. Primary irritation index was 0.33 and 0.16 for $20 \mathrm{~nm}$ and $50 \mathrm{~nm}$ spherical-shaped NPs, respectively, while $50 \mathrm{~nm}$ rod-shaped NMs exhibited negligible redness. An in vivo model for M. furfur infection was generated by passing fungi subcutaneously in rats' skin. Again, $20 \mathrm{~nm}$ particles showed best normalization of skin after 10 days on regular dosing, in comparison with bigger and rod-shaped particles. The statistical clinical score was highest for Ag nanorods, followed by $50 \mathrm{~nm}$ Ag NPs-treated animals. It was observed that $20 \mathrm{~nm}$ spherical particles exhibited the lowest score (0) compared with others as well as with antifungal drugs. Biochemical analysis performed by checking antioxidant enzymatic activities indicated tissue repair and normalization of enzymes and protein concentration by Ag NPs.
\end{abstract}

Keywords: Malassezia furfur, nanorods, in vivo analysis, Wistar rat model

\section{Introduction}

In recent years, skin-related issues pertaining to microbial infections garnered great importance from both scientific and commercial corners. Prominently, Malassezia furfur is a domineering fungus that has received much attention from clinicians and dermatologists. It is a lipo-dependent dimorphic and saprophyte fungus that is a causative organism of pityriasis vesicolor, seborrheic dermatitis, and dandruff conditions constituting major skin and scalp disorders. ${ }^{1}$ These are characterized by dermal inflammation and tissue damage resulting in dryness as well as hyperproliferation, causing flaking, itching, and redness of scalp. These conditions result from proinflammatory-free fatty acids released during lipase activity from the fungi, and M. furfur is considered an etiological factor for dandruff., ${ }^{2,3}$

Currently available mainstay treatment options are based on compounds such as selenium sulfide, imadazoles, and hydropyridones. These antimicrobial agents demonstrate antifungi and antiproliferative effects via disruption of either cellular 
organization integrity or transport of essential macromolecules. Most of these drugs suffer from poor compliance, clinical efficacy, and result in adverse drug effects such as oiliness. $^{4,5}$

These limitations have paved the way for novel nanomaterials (NMs) as potential biocidals with an added advantage of mitigating antibiotic-resistant bacteria and other microbes. Significantly essential oils are being explored as skin and hair quality enhancers as well as potential antimicrobial agents, ${ }^{6}$ but their efficiency is unknown and unpredictable. ${ }^{7}$ Among metallic nanostructures, silver has been in practice for a long period of time in the medical sector, including use as wound and burn dressing materials for controlling bacterial infections. Apparently, $\mathrm{Ag}^{+}$ions are easily liberated from nanomaterial structure on contact with water medium (Equation 1). ${ }^{8,9}$

$$
\mathrm{Ag}_{n}(\mathrm{~s})+\mathrm{O}_{2}(\mathrm{aq})+4 \mathrm{H}^{+} \leftrightarrow \mathrm{Ag}_{n-4}(\mathrm{~s})+4 \mathrm{Ag}^{+}+2 \mathrm{H}_{2} \mathrm{O} \text { (1) }
$$

In contrast to silver ions, nanoparticles (NPs) serve better owing to slow- and long-term release of ions by oxidation of zerovalent as compared to burst release from ion formulations. ${ }^{10}$ NPs can easily permeate cell membranes of living cells and have many fold increase in the cellular uptake of these NPs as compared to the bulk particles. Their cellular accumulation crumbles structural and functional integrity of cells, interjecting and obstructing natural physiological processes. They disrupt DNA via phosphorylation process of prokaryotic cell and bind with thiol groups of cell membrane proteins causing cell rupture and death of organisms. ${ }^{11}$ Reports also suggest NPs are less cytotoxic to mammalian cells than extremely small ions. ${ }^{12}$ Recently, NPs have also been explored as antifungal agents against clinically relevant fungi. Ag NPs have primarily been tested to kill Candida spp. in a research established by Lee et al. ${ }^{13,14}$ They have reported the effect of biological synthesis of Ag NPs using different fungi and have investigated their effect against antibiotic resistant bacteria and M. furfur. Recently, in vitro antimicrobial assessment has also been accomplished by Pant et al, ${ }^{15}$ indicating possible use of Ag spherical NPs in antidandruff shampoos and treatment of dermal diseases.

We inspect silver nanomaterials (Ag NMs) as potential fungistatic material for containing and eradicating scalprelated diseases such as dandruff. Dandruff disease was created on rat models by optimizing conditions for passing fungal infection on their skin. We report for the first time a detailed analysis of uptake of silver nanostructures on diseased rat skin and their treatment with clinical scores as an indication for treatment regime.

\section{Experimental \\ Materials and methods}

Sodium, bis (2-ethylhexyl) sulfosuccinate (AOT [aerosol-OT]), hexane, silver nitrate $\left(\mathrm{AgNO}_{3}\right)$, trisodium citrate, sodium borohydride $\left(\mathrm{NaBH}_{4}\right)$, and aqueous solution of hydrazine chemicals were purchased from Sigma-Aldrich, St Louis, MO, USA. Antifungal drugs such as itraconazole and ketoconazole were obtained from HiMedia Laboratories Pvt. Ltd., India. NMs syntheses were carried out in ultrapure Millipore water. All solvents and reagents were purchased from commercial sources and were used as received unless noted otherwise.

The inoculum suspensions of $M$. furfur (MTCC-1765) obtained from MTCC (Chandigarh, India) were prepared uniformly by the standard procedure. Male albino Wistar rats weighing 250-350 g used in the present study were procured from the institute's animal house, Jamia Hamdard, New Delhi, under specific pathogen-free conditions and facilities for all the in vivo experiments of clinical efficacy and histopathology. All animals were individually housed in standard size polycarbonate cages with controlled conditions of temperature $\left(23^{\circ} \mathrm{C} \pm 1^{\circ} \mathrm{C}\right)$, humidity $(55 \% \pm 10 \%)$ in 12 hours: 12 hours of light and dark cycle, fed with animal feed (Hindustan Pvt. Ltd., India), and water supplied ad libitum. All animal experiments were performed in compliance with regulations and standards of the ethical committee of the institute (CPCSEA/173).

\section{Synthesis of spherical-shaped silver nanoparticles by microemulsion method}

Different sizes and shapes of Ag NPs were obtained by following the chemical processes optimized previously. ${ }^{16,17}$ Reverse micelles of AOT were prepared by dissolving $0.444 \mathrm{~g}$ AOT in $10 \mathrm{~mL}$ hexane, and precise volume of water containing metal component/hydrazine was added to these solutions. The amount of solubilized water is usually expressed as a molar ratio of water to AOT, that is, $W_{0}=$ $\left[\mathrm{H}_{2} \mathrm{O}\right] /[\mathrm{AOT}]$. For the preparation of $\mathrm{Ag} \mathrm{NPs}, 75 \mu \mathrm{L} 0.1 \mathrm{M}$ and $75 \mu \mathrm{L} 1.5 \mathrm{M}$ aqueous solutions of $\mathrm{AgNO}_{3}$ were added to $5 \mathrm{~mL} 0.1 \mathrm{M}$ AOT solution. The resulting solution was stirred for 6 hours on magnetic stirrer to form microemulsion (A). In another set of reactions, $75 \mu \mathrm{L} 0.3 \mathrm{M}$ and $75 \mu \mathrm{L} 0.45 \mathrm{M}$ of hydrazine hydrate solutions were added dropwise to $5 \mathrm{~mL}$ of $0.1 \mathrm{M}$ AOT solution. The molar ratio of hydrazine hydrate to $\mathrm{AgNO}_{3}$ was held constant for all the experiments at a value 
of three. Similarly, this solution was also stirred for 6 hours by magnetic stirrer to form microemulsion, referred to as B. In order to reduce the silver ions, microemulsion (B) containing hydrazine hydrate was added slowly into microemulsion (A) containing $\mathrm{AgNO}_{3}$ drop by drop. After the addition of hydrazine hydrate microemulsion, the resultant solution was subjected to continuous stirring for 6 hours. Subsequently, the color of the microemulsion changed from colorless to a yellowish brown color, indicating the formation of Ag NPs.

\section{Synthesis of rod-shaped silver nanoparticles by aqueous-phase method}

Aqueous solution of $1 \times 10^{-4} \mathrm{M} \mathrm{AgNO}_{3}$ and anhydrous solution of $1 \times 10^{-3} \mathrm{M}$ AOT in hexane were prepared. In $100 \mathrm{~mL}$ of round bottom flask, $50 \mathrm{~mL}$ of $\mathrm{AgNO}_{3}$ solution and $35 \mu \mathrm{L}$ of anhydrous AOT solution were mixed by stirring for 1 hour. After mixing $600 \mu \mathrm{L}$ aqueous solution of $1 \times 10^{-2} \mathrm{M}$ trisodium citrate, it was introduced to above solution and refluxed at $100^{\circ} \mathrm{C}$ with constant stirring for 70 minutes. After refluxing, the reaction mixture became turbid and turned yellowish green. This solution contained both spherical- as well as rod-shaped Ag NPs that were separated by centrifuging the sample at 2,000 rpm for 30 minutes at $25^{\circ} \mathrm{C}$. The $\mathrm{Ag}$ nanorods (NRs) settled at the bottom of their container after centrifugation, while AOT and spherical NPs were removed using a pipette. This separation procedure was repeated several times until supernatant become colorless. NRs were washed by centrifugation process and stored in a colored glass bottle at room temperature till further use.

\section{Characterization of nanomaterials}

Double beam UV-visual spectrophotometer (UV-1601, Shimadzu, Japan) was used to measure the absorbance of synthesized Ag NMs and record optical density. Hydrodynamic radii and stability of synthesized NPs were investigated using a dynamic light scattering (DLS) instrument (Zetasizer Version, 6.1, Malvern, equipped with vertically polarized $\mathrm{He}-\mathrm{Ne}$ laser [632.8 nm] and autocorrelator) at ambient temperatures and constant angle of $90^{\circ}$. Shape, size, and morphology of synthesized NPs and NRs were visually assessed by transmission electron microscope (FE-TEM; JEOL, Tokyo, Japan; JEM-2100) at $200 \mathrm{kV}$ acceleration voltage. Samples were prepared by drop coating $10 \mu \mathrm{L}$ Ag NMs onto carbon-coated copper grids followed by air drying, forming thin layer on surface. X-ray diffraction (XRD) study of completely dried powder of Ag NMs was performed on Philips PW 1830 using a monochromatized X-ray beam with nickel-filtered $\mathrm{CuK} \alpha$ radiation $(\lambda=1.5418 \AA)$ at $40 \mathrm{kV}$. A continuous scan mode was used to collect $2 \theta$ data between $30^{\circ}$ and $40^{\circ}$, with a 0.02 sample pitch and $4 \% \mathrm{~min}$ scan rate.

\section{Evaluation of antifungal properties}

In vitro assessment of antifungal properties of Ag NMs was carried out via plating methodology. Briefly, $M$. furfur, maintained in glycerol stock $15 \%(\mathrm{vol} / \mathrm{vol})$ at $-80^{\circ} \mathrm{C}$, was revived in pityrosporum medium and olive oil broth in an incubator cum shaker $(200 \mathrm{rpm})$ at $28^{\circ} \mathrm{C}$ to obtain $10^{5} \mathrm{CFU} / \mathrm{mL}$ of fungi. A total of $0.1 \mathrm{~mL}$ of $M$. furfur was plated on specialized potato dextrose agar (PDA) plates and sterile paper disks impregnated with predetermined concentrations, ranging from $0.1 \mathrm{mg} / \mathrm{mL}$ to $0.5 \mathrm{mg} / \mathrm{mL}$ of synthesized $\mathrm{Ag}$ NMs were kept on them. Autoclaved and sterilized specialized PDA agar plates were inoculated with $0.1 \mathrm{~mL}$ of M. furfur containing $10^{5} \mathrm{CFU} / \mathrm{mL}$. Sterile disks of Whatman filter paper ( $6 \mathrm{~mm}$ size) impregnated with $100 \mu \mathrm{L}$ predetermined concentrations, ranging from $0.1 \mathrm{mg} / \mathrm{mL}$ to $0.5 \mathrm{mg} / \mathrm{mL}$, of synthesized Ag NMs were kept on them. These plates were incubated for 28 hours at $35^{\circ} \mathrm{C}$ and the resulting zones of inhibition (ZOI) were measured in millimeters. A negative control without Ag NMs, constituted by disk impregnated with fungal filtrate, was also included in the experiment. The efficacy of Ag NMs was compared with commercially available drugs ketoconazole and itracanozxle at $0.5 \mathrm{mg} / \mathrm{mL}$ concentration level. The diameter of fungal colony developing on Ag NM plates was compared with the diameter of the colony obtained on negative control and drugs, and an average of six experiments was used to represent numerical data. minimum inhibitory concentration (MIC)s were noted as the concentration at which no growth was observed.

\section{Skin irritation test and scratching behavior assessment}

Five healthy Wistar male rats, weighing 250-350 g, were selected for the study. An area of $2 \mathrm{~cm}^{2}$ was shaved for each rat to expose sufficient test area, and assay was followed according to Kaur et al. ${ }^{18}$ The rats were divided in five groups as group I (control), group II (standard), group III (20 nm spherical-shaped Ag NPs), group IV (50 nm spherical-shaped Ag NPs), and group V (50 nm rod-shaped Ag NPs). Aqueous solution of formalin (0.7\%) was applied to standard irritant, and the control was untreated. The test sites were visually observed for erythema and edema daily up to 7 days as scored in Table $1 .{ }^{19}$ Scratching behavior of rat models was recorded on a digital camera (Sony W55) by observing their itching tendency for 15 minutes. Rats of groups III, IV, and V were visually observed for developing 
Table I Standards for skin irritation study

\begin{tabular}{|c|c|}
\hline Skin responses & Score \\
\hline \multicolumn{2}{|l|}{ Erythema and eschar formation } \\
\hline No erythema & 0 \\
\hline Very slight erythema (barely perceptible) & 1 \\
\hline Well-defined erythema & 2 \\
\hline Moderate to severe erythema & 3 \\
\hline $\begin{array}{l}\text { Severe erythema (beet redness) to slight eschar } \\
\text { formation (injuries in depth) }\end{array}$ & 0 \\
\hline \multicolumn{2}{|l|}{ Edema formation } \\
\hline No edema & 0 \\
\hline Very slight edema (barely perceptible) & 1 \\
\hline $\begin{array}{l}\text { Slight edema (edges of area well-defined by definite } \\
\text { raising) }\end{array}$ & 2 \\
\hline Moderate edema (raised $\sim 1.0 \mathrm{~mm}$ ) & 3 \\
\hline $\begin{array}{l}\text { Severe edema (raised }>1.0 \mathrm{~mm} \text { and extending beyond } \\
\text { exposure area) }\end{array}$ & 4 \\
\hline Total possible score for irritation & 8 \\
\hline
\end{tabular}

itching or scratching tendency and compared with group I control untreated rats.

\section{In vivo efficacy of $\mathrm{Ag}$ Nano}

\section{Animal model for dandruff}

An animal infection model of dandruff was performed according to protocol of Tatsumi et $\mathrm{al}^{20}$ and Ghannoum et $\mathrm{al}^{21}$ with little modification. Before inoculation, the hairs of both flanks at upper left side and lower right side skin $(3 \mathrm{~cm} \times 3 \mathrm{~cm})$ of each rat were removed by electric hair clipper (MOSER, Germany) followed by the application of hair remover cream for complete removal of hairs. The skin was slightly abrased with sandpaper, which makes it more susceptible to infection. A $200 \mu \mathrm{L}$ of inoculum of fungi containing $2 \times 10^{7} \mathrm{CFU} / \mathrm{mL}$ was applied on the marked area of skin by using a sterile pipette tip and rubbed thoroughly with a sterile cotton-tipped swab (HiMedia Laboratories Pvt. Ltd.) and was passaged thrice on Albino Wistar rat's skin. This was continuously applied for 5 days on the marked area of skin followed by scrubbing and evaluated for fungal infection.

\section{Animal grouping and dosing}

The experimental animals were distributed into seven groups comprising six Wistar rats in each group. Group I rats were designated as control and were treated with saline, and group II was designated as dandruff model and the animals were treated with M. furfur. Groups III and IV were treated with commonly available market drugs, itracanozole and ketoconazole, and were used as standards. Groups V, VI, and VII were treated with $200 \mu \mathrm{L}$ of various sizes and shapes of $\mathrm{Ag}$ NPs $(20 \mathrm{~nm}$ and $50 \mathrm{~nm} \mathrm{Ag} \mathrm{NPs} \mathrm{and} 50 \mathrm{~nm}$ rod-shaped Ag
NRs). The treatment comprising $200 \mu \mathrm{L}$ of drugs or NMs started on day 1 postinfection and was applied tropically daily for 10 consecutive days.

\section{Clinical and mycological evaluation of treatment efficacy of silver nanoparticles}

Clinical and mycological end points were used to determine the efficacies of the antifungal agents tested, and the final assessments were performed on the 14th day postchallenge. Changes (mild, moderate, or severe) in redness, ulceration, and scaling or hair loss at the site of inoculation were visually examined and recorded daily. The infected area marked on the back of each animal was divided into four equal quadrants and were scored accordingly. The redness score was graduated as 0 , normal; 1 , pink; 2 , red; and 3 , violet and the lesion score was graduated: 0 , normal; 1 , papule; 2 , skin scales; 3 , single layer of skin scales and ulcers; and 4, multiple layers of skin scales and ulcers. Areas that had been used for prior specimen sampling were excluded for subsequent clinical evaluation to avoid bias by redness and ulcers due to prior scraping. Scores from the quadrants were summed for each animal (maximum possible score per animal was 20) and used to determine the clinical efficacy of different treatment groups that are expressed as a percentage relative to the infected-untreated control group using the following formula:

$$
\text { Percentage efficacy }=100-\left(T \times \frac{100}{C}\right)
$$

where $T$ is the total score of the test group and $C$ is the total score of the infected-untreated control. The total score for any treatment group signifies the average clinical score from animals in the same group. ${ }^{21}$

\section{Biochemical assays}

These assays aimed to estimate potential effect of Ag NMs in rats and the method is described as supplementary data. The measured biochemical parameters comprised total proteins, ${ }^{22}$ catalase (CAT) ${ }^{23}$ superoxide dismutase (SOD),${ }^{24}$ gluthatione peroxidase (GPx), ${ }^{25}$ malondidialdehyde (MDA), ${ }^{26}$ and total hydroperoxides (THP). ${ }^{27}$

\section{Histopathological examination}

Ag nano-treated groups were compared with control group to observe the histopathology of skin tissues. On the 14th day of experiment, the rats were anesthetized with ether and perfused transcardially with saline. Skin samples were removed and postfixed in $10 \%$ neutral buffered formalin for 
24 hours and processed for histopathological examinations. ${ }^{28}$ After fixation, 3-4 mm slices of tissues were dehydrated and embedded in paraffin. Cross sections of $5 \mu \mathrm{m}$ thickness were cut and followed by washing with xylene, and then the tissues were mounted with DPX (dibutyl phthalate and xylene). Heamatoxylin and eosin stains were used to visualize and differentiate between normal tissue, standard drugs-treated tissue, and Ag nano-treated tissues. Slides were studied for histological changes, and microphotographs were taken using Olympus BX50 microscope (Olympus Corporation, Tokyo, Japan) at Jamia Hamdard, New Delhi, India.

\section{Statistical analysis}

The results are expressed in terms of mean \pm standard deviation. Statistical analysis of all the data between groups receiving no infection vs $M$. furfur infected alone along with those receiving $M$. furfur vs Ag NPs-treated infected rats was performed by unpaired two-tailed Student's $t$-test with consideration of $P$-value $<0.05$ as statistically significant parameter.

\section{Results and discussion Synthesis and characterization of $\mathrm{Ag}$ nanoparticles and nanorods}

Successful synthesis of spherical- and rod-shaped Ag NPs was easily facilitated by AOT-based microemulsion process by varying the concentrations of precursor and reducing agent (Figure S1). Route 1 systematically yielded high concentrations of spherical NPs, whereas NRs of native silver were obtained by route 2 , which were validated primarily by UV-vis spectroscopy. Synthesized NMs were found to stable for 4 months when kept under appropriate conditions of temperature and humidity.

An increase in hydrodynamic size was recorded for NPs in correlation with different $\mathrm{AgNO}_{3}$ concentrations in microemulsion. Ag NPs showed an increase of $20.25 \pm 1 \mathrm{~nm}$ and $50.27 \pm 1 \mathrm{~nm}$ at $75 \mu \mathrm{L}$ and $100 \mu \mathrm{L}$ of $0.1 \mathrm{M} \mathrm{AgNO}_{3}$, respectively. This is attributed to enhanced layering of formed seed particles with more native silver atoms gradually released in microemulsion, thereby maintaining polydispersity and stability. Spherical-shaped Ag NPs of $20 \mathrm{~nm}$ and $50 \mathrm{~nm}$ showed absorption peaks at $406 \mathrm{~nm}$ and $425 \mathrm{~nm}$, respectively.

Route 2 of aqueous-phase synthesis proceeds with the reverse micelle formation of water droplets of citrate ions in hexane with self-seeding template-less mechanism stabilized by AOT. The small water droplets act as reactor site for conversion of salt to native metal on reduction in organic solvent. ${ }^{29}$ The obtained NMs showed two plasma bands in
UV-vis absorption spectrum at $531 \mathrm{~nm}$ and $432 \mathrm{~nm}$ corresponding to longitudinal and transverse plasmonic bands, respectively, confirming the formation and isolation of $\mathrm{Ag}$ NRs (Figure S2). The time scale analysis clearly revealed transformation of particulate structure to rod at $70^{\circ} \mathrm{C}-80^{\circ} \mathrm{C}$, where greenish yellow color indicated reduction of salt by citrate. The exact mechanism of the synthesis is yet to be established, but it is predicted that concentration of mild reducing agent plays a pivotal role in anisotropic reduction of $\mathrm{AgNO}_{3}$, usually aspect ratio decreases with decreasing reducing agent. ${ }^{30}$

The number of water molecules added per molecule of AOT $W_{0}$, present in micelles, is representative of their core size, and it has been observed in AOT microemulsion systems that the water pool radius increases with the water content. ${ }^{31}$ The UV-vis spectra of the Ag NPs are shown in Figure S2 at $W_{0}=10$ and 15 . It was observed that with the increase in water contents in microemulsion, core size increased and formed bigger NPs than with lower water contents, which favorably produce small reverse micelles. The red shift in wave length from 406 to $425 \mathrm{~nm}$ (Figure S2) was also observed as the particles size increased from 20 to $50 \mathrm{~nm}$, when $W_{0}$ was increased from 10 to 15 at constant silver concentration. At low water content, the water solubilized in the polar core is bound by surfactant molecules, which increases the boundary strength and decreases the intermicellar exchange rate. This process induces formation of monodisperse $\mathrm{Ag}$ NPs with small particle size. However, as water content increases, this bounding loosens up, creating macro zones and facilitating water pool exchange via collisions, resulting in coprecipitation of compounds solubilized in two different reverse micelles to complete more quickly. Reactants would be rapidly transferred from one water core to another, and thus the resultant particle size is large and the size distribution becomes relatively wide.

The well-defined shape that can be visualized under TEM (Figure 1) suggested that route 1 results in spherical NPs having narrow size distribution, and aqueous-phase reaction yield rod-shaped particles. TEM micrographic analysis also confirmed the relationship between the size and precursor amount concentration. These analyses established that process 2 - aqueous-phase reaction-yielded rod structures of Ag NMs of $50 \mathrm{~nm}$ diameter. Figure 1D illustrates the XRD pattern of powdered Ag NRs that depicted four different peaks at $2 \theta 39^{\circ}, 45^{\circ}, 64^{\circ}$, and $73^{\circ}$ corresponding to [ 1111$]$,

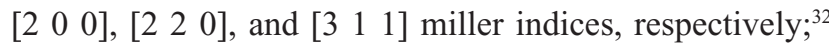
therefore, the synthesized Ag NRs are found to be having regular face-centered cubic organization. 

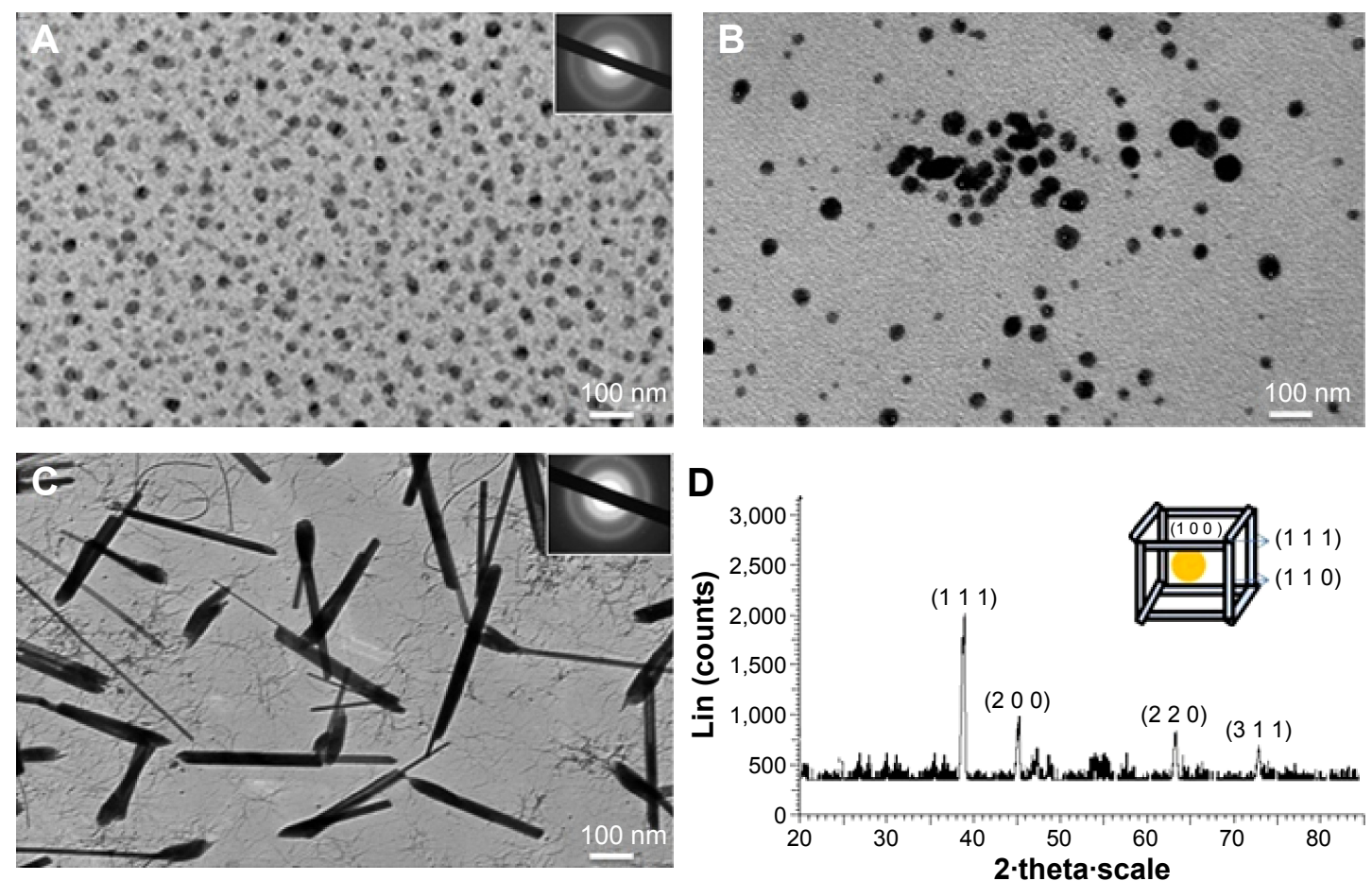

Figure I TEM micrograph.

Notes: (A) $20 \mathrm{~nm}$ spherical-shaped Ag NPs; (B) $50 \mathrm{~nm}$ with spherical-shaped Ag NPs; (C) TEM image showing $50 \mathrm{~nm}$ of rod-shaped Ag NPs. The insets show the diffraction pattern recorded by aligning the electron beam perpendicular to one of the square faces of an individual nanoparticle. (D) XRD pattern of Ag NR.

Abbreviations: TEM, transmission electron microscopy; NPs, nanoparticles; XRD, X-ray diffraction; NR, nanorod.

\section{In vitro biocidal efficiency}

Antifungal activity of the prepared Ag NMs was investigated against $M$. furfur, which is responsible for grave dermatological disorders like pityriasis versicolor and seborrheic dermatitis along with dandruff. Ag NMs and known antifungal drugs such as ketoconozole as well as itracanozole were challenged with an inoculum of $10^{5} \mathrm{CFU} / \mathrm{mL}$ of fungi, and killing capacity was quantifiably measured by denoting ZOI on pityrosporum PDA medium by agar diffusion method. Figure S3 shows the photographic image of antimicrobial test denoting ZOI for different agents. It was observed that $20 \mathrm{~nm}$ NPs created maximum ZOI than $50 \mathrm{~nm}$ spherical NPs as well as $50 \mathrm{~nm}$ NRs at different concentrations of Ag NMs, ranging from $0.2 \mathrm{mg} / \mathrm{mL}$ to $0.5 \mathrm{mg} / \mathrm{mL}$. Pyrrole-based market drugs had no response with negligible ZOI even at highest tested concentration of $0.5 \mathrm{mg} / \mathrm{mL}$ as presented in the inset of Figure 2, indicating superior characteristics of Ag NMs.

Spherical-shaped Ag NPs of $20 \mathrm{~nm}(0.5 \mathrm{mg} / \mathrm{mL})$ exhibited maximum antifungal activity in contrast to $50 \mathrm{~nm}$ rodshaped Ag NPs, demonstrating minimum killing. These results indicate size and shape-dependent antifungal activity of Ag NMs. Smaller-sized Ag NPs are more efficient for antifungal application due to higher breaching of fungal cell wall and interfering with the cellular respiration, leading to cell death. This is the first report to demonstrate that $M$. furfur mitigation activity dependens on structural differences of NMs, which will become important in further analyzing shampoos as well as drug delivery formulations for scalp treatment of fungal infection (work in progress). Antifungal activity linearly increases with increase in concentration of NMs tested against $10^{5} \mathrm{CFU} / \mathrm{mL}$ of fungi. The MICs against $10^{5} \mathrm{CFU} / \mathrm{mL}$ of $M$. furfur were $0.2 \mathrm{mg} / \mathrm{mL}$ for $20 \mathrm{~nm}$ and $50 \mathrm{~nm} \mathrm{Ag} \mathrm{NPs} \mathrm{and} 0.3 \mathrm{mg} / \mathrm{mL}$ of rod-shaped materials. These results show that Ag NMs have potent antimicrobial activity even at low concentrations.

\section{Skin irritation study}

Once in vitro antifungal efficiency in relation to size was established, we sought to evaluate in vivo antimicrobial effects of Ag NPs to understand their effects on rat's skin surface. Skin of all rat groups showed visual observation for irritation marked using redness scoring (Figure S4) on exposure to NMs at different time periods. Skin irritation studies on Rat gave 0 scale for erythma as well as 0 level scale for edema as compared to the standard formalin solution. The results give clear indication of pronounced topical irritation with small spherical NPs owing to their enhanced reactivity as compared with bigger dimensions as well as shape. 

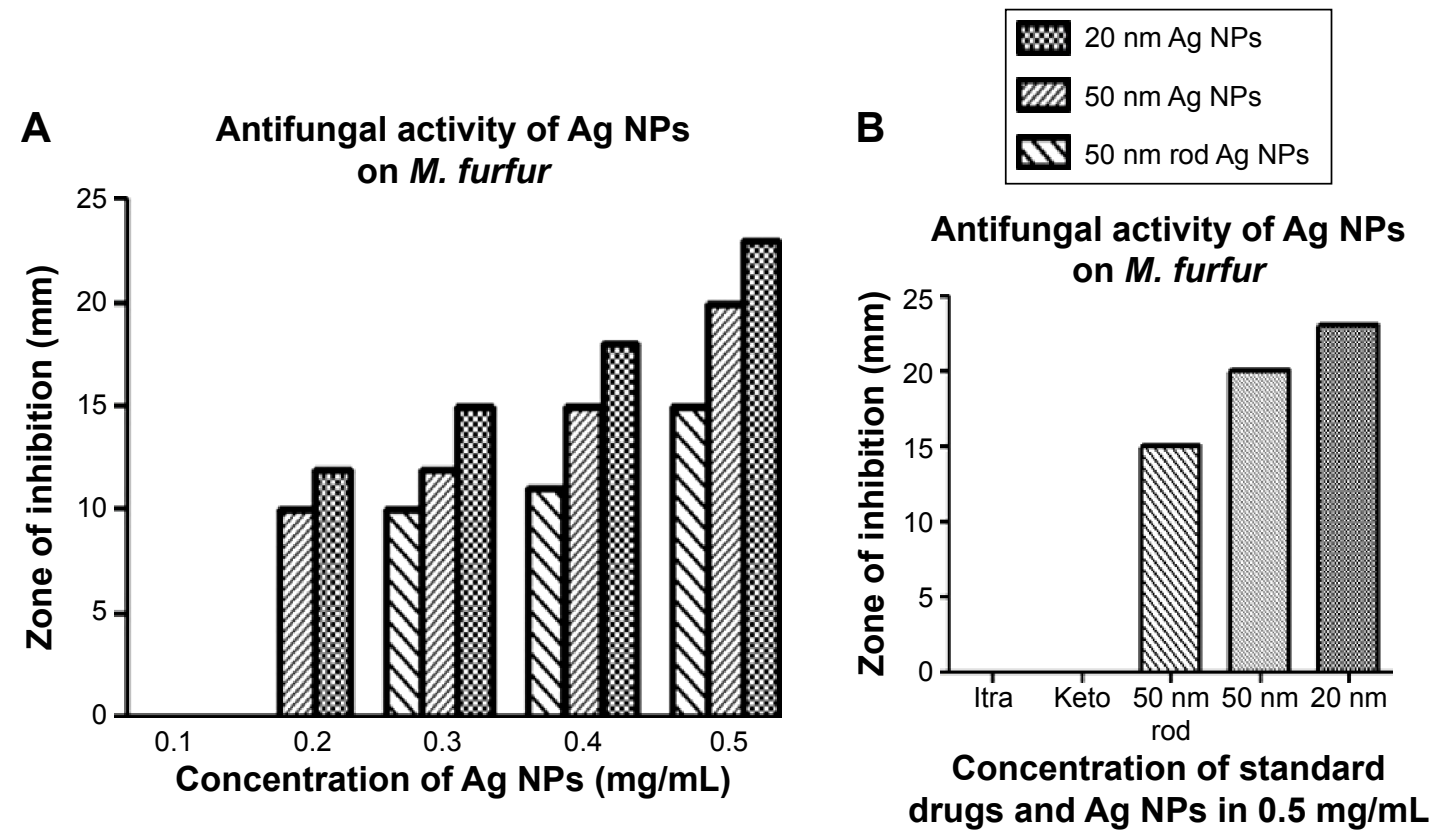

Figure 2 Comparison of different antifungal agents and correlation of their concentration with biocidal efficiency.

Notes: (A) Represents the concentration dependent antifungal activity of Ag NPs on M. furfur. (B) Represents the comparative antifungal activity of Ag NPs with standard drugs.

Abbreviations: NPs, nanoparticles; M. furfur, Malassezia furfur.

The results of skin irritation test (Table 2) indicate that Ag NPs do not produce any dermatological reaction and were well tolerated by rats showing no drastic visual flakes formation and inflammation. Primary irritation index (PII) was calculated as 0.33 and 0.16 for $20 \mathrm{~nm}$ and $50 \mathrm{~nm}$ spherical NPs, respectively, while the rats in direct contact with $50 \mathrm{~nm}$ rod-shaped NMs exhibited negligible redness and were marked 0 scores. These results confirmed slightly more irritation tendency of spherical-shaped NMs, but they were chosen for further studies on rats due to their higher antimicrobial efficiency than Ag NR. This also serves as an indirect proof elucidating more penetration capabilities as well as reactivity of small spherical particles than rod-shaped Ag NPs.

Itching is an unpleasant sensation acting as physiological mechanism to support the defense against external agents, particularly aggravated in seborrheic dermatitis and other dermatological complications. Rats of III, IV, and V groups were recorded by camera for 15 minutes after the treatment of different Ag NMs and their scratching pattern was compared with normal untreated rats. No adverse dermatological effects of NMs occlusion in rat's skin were noted as measured in irritation studies, indicating no specific reaction of Ag NMs on the surface. The numbers of scratch sequences were lower for $50 \mathrm{~nm}$ NRs as compared to spherical NPs, similar to the results obtained for other irritation studies. This is attributed to pronounced reactivity and inclusion of $20 \mathrm{~nm}$ and $50 \mathrm{~nm}$ spherical NPs (Figure S5).

\section{Clinical and mycological treatment analysis}

After creating dandruff model, an initial investigation was made to determine the in vivo antifungal effects of Ag NMs. The manifestation and progression of infection were visually evident

Table 2 Rat skin irritation test with all nanomaterials and drugs

\begin{tabular}{lllllll}
\hline & Time (h) & Score & & & \\
\cline { 2 - 6 } & & $\begin{array}{l}\text { Rat I } \\
\text { (control) }\end{array}$ & $\begin{array}{l}\text { Rat 2 } \\
\text { (formalin) }\end{array}$ & $\begin{array}{l}\text { Rat 3 (20 nm } \\
\text { Ag NPs) }\end{array}$ & $\begin{array}{l}\text { Rat 4 (50 nm } \\
\text { Ag NPs) }\end{array}$ & $\begin{array}{l}\text { Rat 5 (50 nm } \\
\text { Ag NR) }\end{array}$ \\
\hline Erythema and scar & 6 & 0 & 1 & 0 & 0 & 0 \\
& 12 & 0 & 2 & 0 & 0 & 0 \\
Edema & 48 & 0 & 3 & 2 & 0 & 0 \\
& 6 & 0 & 0 & 0 & 0 & 0 \\
Primary irritation index (PII) & $\mathrm{I}$ & 0 & $\mathrm{I}$ & 0 & 0 \\
\hline
\end{tabular}

Abbreviations: h, hour; NPs, nanoparticles; NR, nanorod. 
on the skin of rats that developed red patches, flakes, and scales, increasing gradually with time. Different groups of rats were subcutaneously delivered with single dose of $200 \mu \mathrm{L}$ of antimicrobial agent on day 1 postinfection for 10 consecutive days. They were marked by clinical scores clearly indicating the extent of redness in comparison to normal skin of control set (Table 3 ). On continued application of Ag NMs and other drugs, regression in redness was visible (Figure 3 ) and marked on the final assessment on tenth day of clinical and mycological investigation.

Furthermore, a contingency statistical analysis corroborated these findings demonstrating significant variation in percent efficacy for each treatment group. The mean clinical score for Ag NRs was highest at any given time followed by a mean score for $50 \mathrm{~nm} \mathrm{Ag} \mathrm{NPs-treated} \mathrm{animals} \mathrm{comprised}$ in group 2 (aqueous solution of formalin). It was observed that $20 \mathrm{~nm}$ spherical particles exhibited the lowest score 0 compared to others as well as with antifungal drugs. The same trend was denoted for the increase in lesion formation on infection and their eventual decrease on treatment with all materials under investigation. These results confirmed substantial treatment of spherical shape and small size NPs that penetrate easily in different layers of skin and have higher capabilities for interacting with fungal cells. Largesized particles, including those with rod-like morphology, hamper their deep penetration and killing of fungus via active DNA damage or cell rupture mechanisms. ${ }^{33}$ Nanostructures release silver ions in control manner owing to slow oxidation on rat skin surface, prolonging the treatment effects and efficacy of the fungistatic agent. No mortality or acute intoxication or adverse skin damages characterized the treatment methodology during the observation period of 15 days. Behavior of rats during this time frame was normal. On final culmination of studies, the animals were sacrificed, and no pathological side effects or deformities were observed in any organ.

\section{Biochemical assay}

The activities of the antioxidant enzymes - CAT, SOD, GPx, MDA, and THP of all groups were measured as an important indication of treatment process, and the values are reported in Table 4. These antioxidative enzymes work as defense systems that manage reactive oxygen species, resulting in oxidative stress under high concentration or inadequate removal conditions. This severely affects metabolic functioning while damaging cellular biomolecules irreversibly. ${ }^{34}$ Enzyme activities and protein concentrations were calculated using kits operated using skin of all the six rats in each group taken as an average and including standard deviation. These concentration values for control group without fungal infection and medication were considered the desired levels for comparison with the rest of the sets. Diseased condition of group II animals deleteriously reduced the levels of CAT, SOD, GPx, and THP while increased the levels of MDA from that of control group because of fungal attack. The reduction amounted to two- to fourfolds for tested parameters, which is significant in assessing the grave situation of skin infection.

On introduction of Ag NPs and drugs, these levels further changed indicating tissue repair and normalization of enzymes and proteins concentration. Significant increase in the CAT, SOD, GPx, THP and decrease in MDA concentration were observed prominently for groups V, VI, and VII as compared to groups III and IV, verifying enhanced mitigation of fungal growth by Ag NMs. It is clear that Ag NMs, particularly $20 \mathrm{~nm}$ Ag NPs, restore activities and concentrations of CAT and GPx that are considered to be primary antioxidants accountable for direct removal of reactive oxygen species. A total of $25 \%-50 \%$ improvement in concentration levels was observed for Ag NMs than both drugs.

Further, treatment with Ag NMs doubled CAT and total proteins concentrations, increased SOD, GPx, and THP by $\sim 3.5$ times, whereas MDA was reduced to half values than diseased condition (group II). The maximum effect was seen for $20 \mathrm{~nm}$ NPs that attained the desired values as that of control. The order of correctness of diseased condition can be defined in ascending configuration of their effectiveness as It $<$ Ket $<$ Ag NR $<50$ nm NP $<20$ nm spherical NPs. This is an important analysis in understanding minimal

Table 3 Clinical and mycological evaluation of treatment efficacy of silver nanoparticles in rat models

\begin{tabular}{|c|c|c|c|c|c|c|c|c|}
\hline \multirow[t]{2}{*}{ S no } & \multirow[t]{2}{*}{ Group factor } & \multirow[t]{2}{*}{ Control } & \multirow[t]{2}{*}{ Infected } & \multirow{2}{*}{$\begin{array}{l}\text { Treated } \\
\text { (itracanzole) }\end{array}$} & \multirow{2}{*}{$\begin{array}{l}\text { Treated } \\
\text { (ketocanzole) }\end{array}$} & \multicolumn{3}{|c|}{ Treated with Ag NPs } \\
\hline & & & & & & $20 \mathrm{~nm}$ & $50 \mathrm{~nm}$ & $50 \mathrm{~nm}$ \\
\hline 1 & Redness & 0 & 3 & 2 & I & 1 & I & 1 \\
\hline 2 & Ulceration & 0 & 3 & 2 & 2 & 0 & 0 & 1 \\
\hline 3 & Scaling & 0 & 3 & 2 & 2 & 0 & I & 1 \\
\hline 4 & Total score & 0 & 9 & 6 & 5 & $\mathrm{I}$ & 2 & 3 \\
\hline 5 & Efficacy (\%) & NA & NA & 33.34 & 44.45 & 88.89 & 77.78 & 66.67 \\
\hline
\end{tabular}

Abbreviations: NPs, nanoparticles; NA, not applicable. 

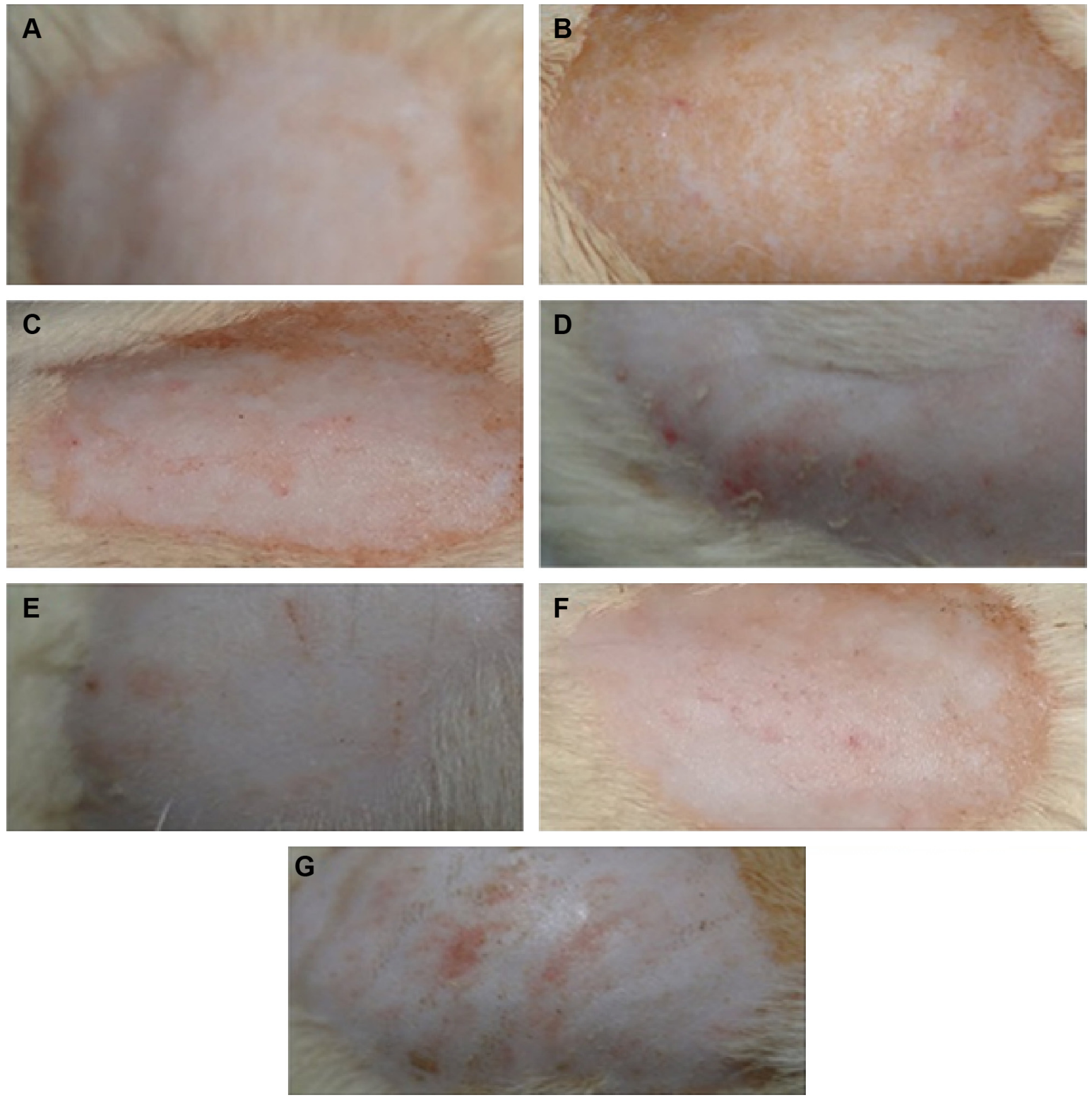

Figure 3 Skin photographs of the dorsal surface of rats.

Notes: (A) Control group I showing no redness, no inflammation; (B) M. furfur diseased group, scales on the skin; (C) and (D) Groups III and IV treated with itracanozole and ketoconazole, respectively, showing skin with decreased scales as compared to Group II with pinkish color; (E) Group V (20 nm spherical Ag NPs) showing complete treatment of $M$. furfur as compared to Group II; (F) and (G) Groups VI and VII (50 nm spherical- and rod-shaped Ag NPs) also showed normalization of the skin but less as compared to group $V$.

Abbreviations: M. furfur, Malassezia furfur; NPs, nanoparticles.

Table 4 Results of biochemical activity assays in different groups of studied rats

\begin{tabular}{|c|c|c|c|c|c|c|}
\hline Groups of animals & $\begin{array}{l}\text { CAT (KU/g } \\
\text { protein) }\end{array}$ & $\begin{array}{l}\text { SOD }(K U / g \\
\text { protein) }\end{array}$ & $\begin{array}{l}\text { GPx (Ul/g } \\
\text { protein) }\end{array}$ & $\begin{array}{l}\text { MDA (mmol/g } \\
\text { tissue) }\end{array}$ & $\begin{array}{l}\text { THP }(\mathrm{mmol} / \mathrm{g} \\
\text { protein) }\end{array}$ & $\begin{array}{l}\text { Total protein } \\
\text { (mg/dL) }\end{array}$ \\
\hline Group I (control) & $74.27 \pm 4.64$ & $70.92 \pm 11.34$ & $41.22 \pm 2.11$ & $18.03 \pm 1.97$ & $8.40 \pm 1.5$ & $7.91 \pm 0.49$ \\
\hline Group II (diseased model) & $34.98 \pm 3.53$ & $17.80 \pm 2.60$ & $9.00 \pm 1.37$ & $47.47 \pm 0.64$ & $2.63 \pm 0.20$ & $4.69 \pm 1.2$ \\
\hline Group III (itracanozole) & $49.43 \pm 4.65$ & $32.53 \pm 3.21$ & $17.02 \pm 2.63$ & $31.21 \pm 2.81$ & $4.24 \pm|.4|$ & $5.53 \pm 0.88$ \\
\hline Group IV (ketoconazole) & $48.28 \pm 5.73$ & $34.21 \pm 6.11$ & $19.87 \pm 3.72$ & $34.72 \pm 3.32$ & $4.92 \pm 2.1$ & $5.2 \mathrm{I} \pm \mathrm{I} .5$ \\
\hline Group V (20 nm spherical Ag NPs) & $72.32 \pm 3.21$ & $68.87 \pm 3.87$ & $38.67 \pm 4.11$ & $19.93 \pm 4.72$ & $7.87 \pm 0.89$ & $7.74 \pm 1.56$ \\
\hline Group VI (50 nm spherical Ag NPs) & $69.54 \pm 2.73$ & $64.67 \pm 3.63$ & $35.83 \pm 3.39$ & $23.21 \pm 3.21$ & $7.1 I \pm I .1$ & $6.77 \pm 3.2$ \\
\hline Group VII (50 nm rod Ag NPs) & $62.73 \pm 3.72$ & $59.32 \pm 2.32$ & $32.64 \pm 2.79$ & $26.54 \pm 5.11$ & $6.93 \pm 0.68$ & $6.13 \pm 2.22$ \\
\hline
\end{tabular}

Abbreviations: CAT, catalase; SOD, superoxide dismutase; GPx, gluthatione peroxidase; MDA, malondidialdehyde; THP, total hydroperoxides; NPs, nanoparticles. 

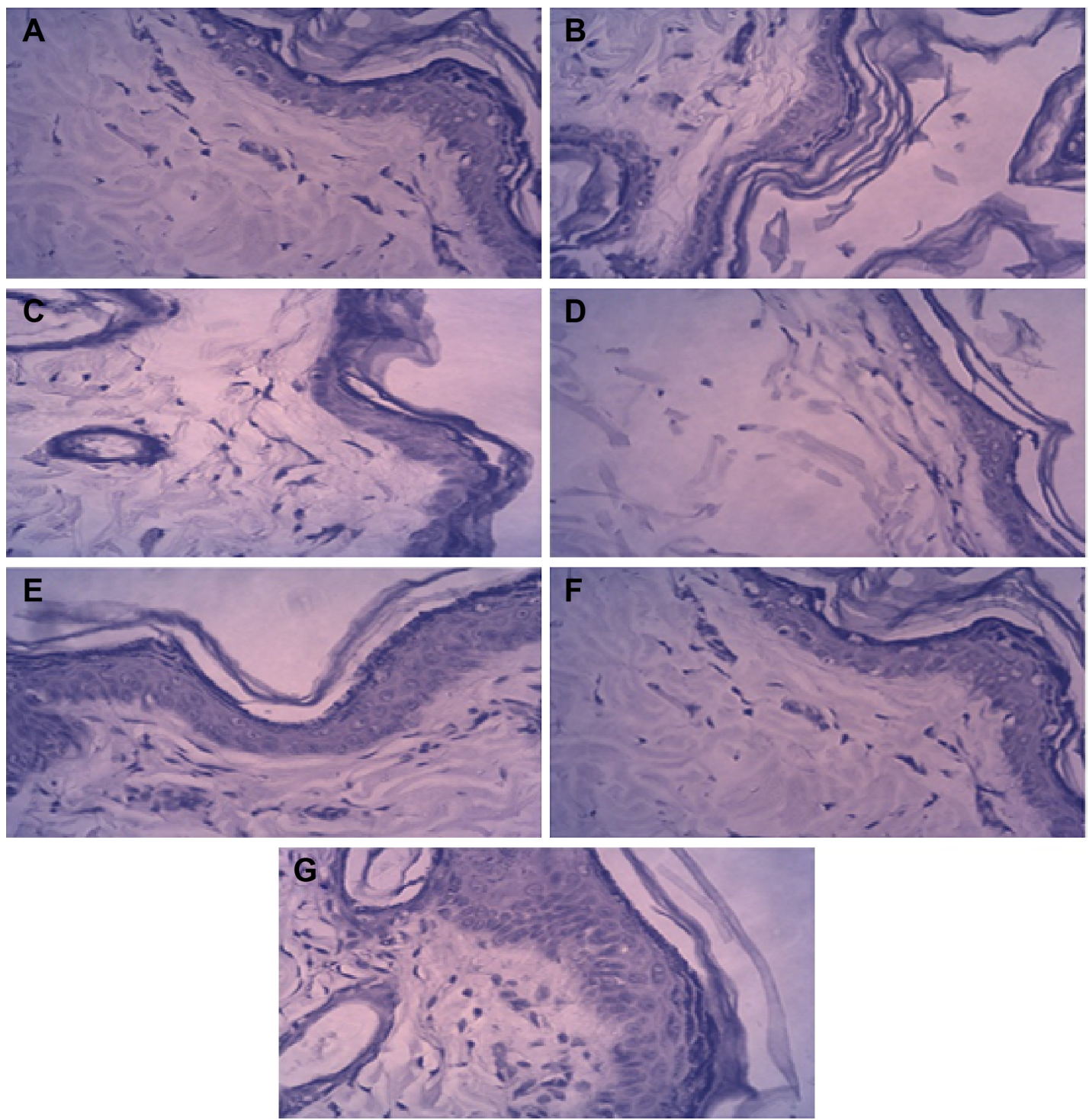

Figure 4 Histopathological microphotographs of different groups of studied rats.

Notes: (A) Control I; (B) M. furfur diseased model group II; antifungal agent-treated groups; (C) III (itracanozole); (D) IV (ketoconazole); (E) V (20 nm spherical-shaped Ag NPs); (F) VI (50 nm spherical), and (G) VII (50 nm rod-shaped Ag NPs).

Abbreviations: M. furfur, Malassezia furfur; NPs, nanoparticles.

cytotoxicity of Ag NMs as oxidative stress is less in rats treated with them. These results signify that Ag NMs exert cytoprotective effects on infected mice with antioxidative and peroxidant properties, restoring the activities of major biochemical enzymes in the process at the used concentration parameters. ${ }^{35}$ The complete toxicity evaluation is currently under progress.

\section{Histopathological evaluation}

Histopathological results of skin are shown in Figure 4. Control group I presented normal histology of epidermis and dermis. Group II (diseased model) exhibited proliferation of epidermis with hyperkeratosis, in which the stratum corneum thickens. The dermis presents discreet chronic inflammatory infiltrates. The experimental groups III and IV (itracanozole and ketoconazole) also exhibited thick proliferation of the epidermis with a low inflammatory response in dermis. With the introduction of $20 \mathrm{~nm}$ Ag NPs in group V rats, no significant proliferation of the epidermis and stratum corneum hyperkeratosis was observed, while groups VI and VII (50 nm spherical and $50 \mathrm{~nm}$ rod-shaped Ag NPs, respectively) exhibited mild thickening of epidermis and mild stratum corneum hyperkeratosis.

\section{Conclusion}

Spherical- and rod-shaped Ag NMs have been successfully prepared of $20 \mathrm{~nm}, 50 \mathrm{~nm}$, and $50 \mathrm{~nm}$ sizes, respectively. These NMs exhibit excellent antifungal activity eradicating 
$10^{5} \mathrm{CFU} / \mathrm{mL}$ of $M$. furfur with an effective MIC of 0.2, 0.3, and $0.5 \mathrm{mg} / \mathrm{mL}$ for 20 and $50 \mathrm{~nm}$ spherical NPs and $50 \mathrm{~nm}$ NRs, respectively. In addition, these NMs have been found to be superior to tested drugs. Fungal infection passed on rat model induced with dandruff state was successfully treated with synthesized NPs, demonstrating differential mitigation efficacy. PII was calculated as 0.33 and 0.16 for $20 \mathrm{~nm}$ and $50 \mathrm{~nm}$ spherical NPs, while NRs, respectively, exhibited negligible redness and were marked 0 scores. The mean clinical scores marked for redness and flakes on treatment with Ag NMs indicate working of these antifungal agents, which is topically explained by their easy entry into cellular organization by breaching cell wall and membranes. Importantly, $20 \mathrm{~nm}$ NPs yielded best results at the end of treatment period followed by $50 \mathrm{~nm}$ spheres and rods. These particles responded in the most efficient manner against induced dandruff and dermatophytes as validated by contingency statistical analysis indicated by mean clinical score and descending order of NPs, $50 \mathrm{~nm}$ NPs, $20 \mathrm{~nm}$ NPs (0). These results were also expressed through biochemical and histopathological studies. Small-sized spherical Ag NPs can be used as an important cost-effective fungistatic agent in formulations for treating scalp problems, since they can be produced in larger quantities and very small amount is required for the desired effect.

\section{Acknowledgments}

The authors are thankful to Dr GN Qazi, Vice-chancellor, Jamia Hamdard, New Delhi, India, for his support in carrying out this work. Financial assistance from Department of Science and Technology, India, is greatly acknowledged.

\section{Disclosure}

The authors report no conflicts of interest in this work.

\section{References}

1. University of Adelaide. Mycology Online; 2015. Available from: http://www.mycology.adelaide.edu.au/Mycoses/Superficial/ Malassezia_infections/. Accessed April 15, 2014.

2. Ravichandran G, Bharadwaj SV, Kolhapure SA. Evaluation of the clinical efficacy and safety of "anti-dandruff shampoo" in the treatment of dandruff. Antiseptic. 2004;201(5):5-8.

3. Shuster $S$. The aetiology of dandruff and the mode of action of therapeutic agents. Br J Dermatol. 1984;111(2):235-242.

4. Sanfilippo A, English JC 3rd. An overview of medicated shampoos used in dandruff treatment. Pharm Ther. 2006;31:396-340.

5. Cutsem VJ, Gerven VF, Fransen J. The in vitro antifungal activity of ketoconazole, zinc pyrithione, and selenium sulfide against pityrosporum guinea pigs. J Am Acad Dermatol. 1990;22(6):993-998.

6. Wuthi-Udomlert M, Chotipatoomwan P, Panyadee S, Gritsanapan W. Inhibitory effect of formulated lemongrass shampoo on malassezia furfur: a yeast associated with dandruff. Southeast Asian J Trop Med Public Health. 2011;42(2):363-369.
7. Prabhamanju M, Shankar SG, Babu K, Ranjith MS. Herbal vs chemical substances as antidandruff ingredients: which are more effective in the management of dandruff? An overview. Egypt Dermatol Online J. 2009;5(2):8

8. Liu J, Sonshine DA, Shervani S, Hurt RH. Controlled release of biologically active silver from nanosilver surfaces. ACS Nano. 2010;4(11): 6903-6913.

9. Zhang W, Yao Y, Sullivan N, Chen Y. Modeling the primary size effects of citrate-coated silver nanoparticles on their ion release kinetics. Environ Sci Technol. 2011;45(10):4422-4428.

10. De Gusseme B, Sintubin L, Baert L, et al. Biogenic silver for disinfection of water contaminated with viruses. Appl Environ Microbiol. 2010;76(4):1082-1087.

11. Feng QL, Wu J, Chen GQ, Cui FZ, Kim TN, Kim JO. A mechanistic study of the antibacterial effect of silver ions on Escherichia coli and Staphylococcus aureus. J Biomed Mater Res. 2000;52(4): 662-668.

12. De Lima R, Seabra AB, Duránd N. Silver nanoparticles: a brief review of cytotoxicity and genotoxicity of chemically and biogenically synthesized nanoparticles. J Appl Toxicol. 2012;32(11):867-879.

13. Lee J, Kim KJ, Sung WS, et al. The silver nanoparticle (nano-Ag): a new model for antifungal agents in nanotechnology and nanomaterials. In: Perez DP, editor. Silver Nanoparticles. (Chap. 15). Rijeka: InTech; 2010.

14. Joshi PA, Bonde SR, Gaikwad SC, Gade AK, Abd-Elsalam KA, Rai MK. Comparative studies on synthesis of silver nanoparticles by Fusarium oxysporum and Macrophomina phaseolina and it's efficacy against bacteria and Malassezia furfur. J Bionanosci. 2013;7:1-8.

15. Pant G, Nayak N, Prasuna GR. Enhancement of antidandruff activity of shampoo by biosynthesized silver nanoparticles from Solanum trilobatum plant leaf. Appl Nanosci. 2013;3:431-439.

16. Bagwe RP, Khilar KC. Different sizes and shapes of silver nanoparticles were obtained by following the chemical processes. Langmu. 2000;16:905-910.

17. Guidelli EJ, Ramos AP, Zaniquelli ME, Baffa O. Preparation of colloidal silver nanoparticles by chemical reduction method. Korean $J$ Chem Eng. 2009;26(1):153-155.

18. Kaur LP, Garg R, Gupta GD. Development and evaluation of topical gel of minoxidil from different polymer bases in application of alopecia. Int J Pharm Sci. 2010;2(3):43-47.

19. Alves EN, Presgrave Rde F, Presgrave OA, Sabagh FP, de Freitas JC, Corrado AP. An in vitro haemolysis test as an alternative to the draize test for ocular irritation. Comp Haematol Int. 1994;4:49-54.

20. Tatsumi Y, Yokoo M, Arika T, Yamaguchi H. In vivo fungicidal effect of KP-103 in a guinea pig model of interdigital tinea pedis determined by using a new method for removing the antimycotic carryover effect. Microbiol Immunol. 2002;46(7):433-439.

21. Ghannoum MA, Long L, Kim HG, Cirino AJ, Miller AR, Mallefet P. Efficacy of terbinafine compared to lanoconazole and luliconazole in the topical treatment of dermatophytosis in a guinea pig model. Med Mycol. 2010;48(3):491-497.

22. Lowry O, Rosebrough H, Farr AL, Randall RJ. Protein measurement with the folin phenol reagent. J Biol Chem. 1951;193(1):265-275.

23. Van Lente F, Pepoy M. Coupled-enzyme determination of catalasa activity in erythrocytes. Clin Chim Acta. 1990;36(7):1339-1343.

24. Minami M, Yoshikawa HA. Simplified assay method of superoxide dismutase activity for clinical use. Clin Chim Acta. 1979;92(3): 337-342.

25. Faraji B, Kang HK, Valentine JL. Methods compared for determining glutathione peroxidasa activity in blood. Clin Chim Acta. 1987;33(4): $539-543$.

26. Gérard-Monnier D, Erdelmeier I, Régnard K, Moze-Henry N, Yadan JC, Chaudière J. Reactions of 1-methyl-2-phenylindone with malondialdehyde and 4-hydroxyalkenals. Analytical applications to a colorimetric assay of lipid peroxidation. Chem Res Toxicol. 1998;11(10):1176-1183.

27. Wolff SP. Ferrous ion oxidation in the presence of the ion indicator xylenol orange for the measurement of hydroperoxides: the FOX assay. Method Enzymol. 1994;233C:182-189. 
28. Yadav D, Chaudhary AA, Garg V, et al. In-vitro toxicity and antihyperglycemic activity of a newly developed polyherbal formulation (MACST/001) in streptozotocin-induced diabetic Wistar rats. Protoplasma. 2013;250(3):1741-1749.

29. Zhou J, Zhou G, Wang R, Lu M. Synthesis in aqueous phase and characterization of silver nanorods and nanowires. Mater Sci Pol. 2009; 27:73-78.

30. Sarkar P, Bhui DK, Bar H, et al. Aqueous-phase synthesis of silver nanodiscs and nanorods in methyl cellulose matrix: photophysical study and simulation of UV-Vis extinction spectra using DDA method. Nanoscale Res Lett. 2010;5(10):1611-1618.

31. Abel S, Waks M, Marchi M, Urbach W. Effect of surfactant conformation on the structures of small size nonionic reverse micelles: a molecular dynamics simulation study. Langmu. 2006;22(22):9112-9120.
32. Anwar MF, Yadav D, Kapoor S, Chander J, Samim M. Comparison of antibacterial activity of Ag nanoparticles synthesized from leaf extract of Parthenium hystrophorus $\mathrm{L}$ in aqueous media and gentamicin sulphate: in-vitro. Drug Dev Ind Pharm. 2015;41(1):43-50.

33. Wijnhoven SWP, Peijnenburg WJ, Herberts CA, et al. Nano-silver - a review of available data and knowledge gaps in human and environmental risk assessment. Nanotoxicology. 2009;3(2):109-138.

34. Matés JM, Pérez-Gómez C, Núñez de Castro I. Antioxidant enzymes and human diseases. Clin Biochem. 1999;32(8):595-603.

35. Shayesteh TH, Khajavi F, Ghasemi H, Zijoud SMH, Ranjbar A. Effects of silver nanoparticle (Ag NP)on oxidative stress, liver function in rat: hepatotoxic or hepatoprotective? Issues Biol Sci Pharmaceut Res. 2014; 2(5):040-044 


\section{Supplementary materials}

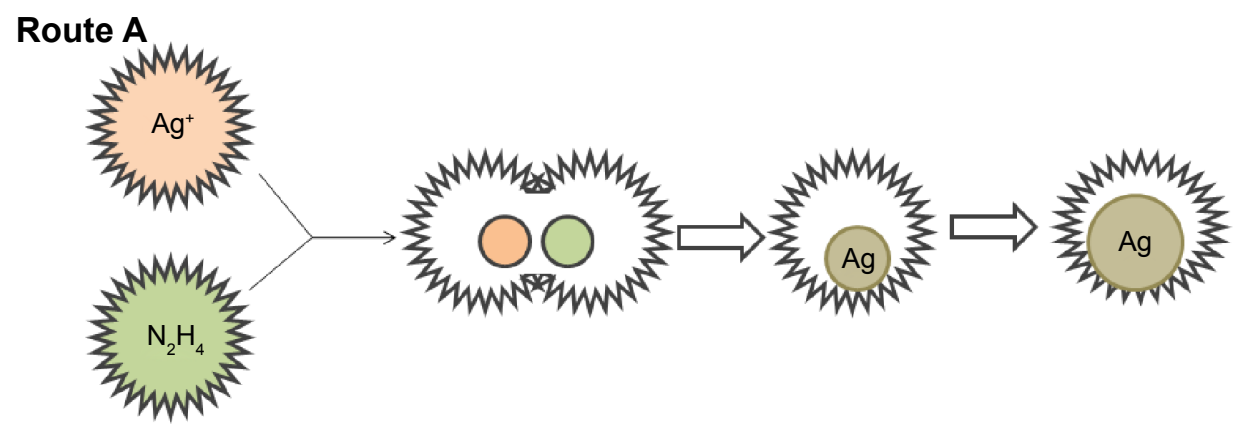

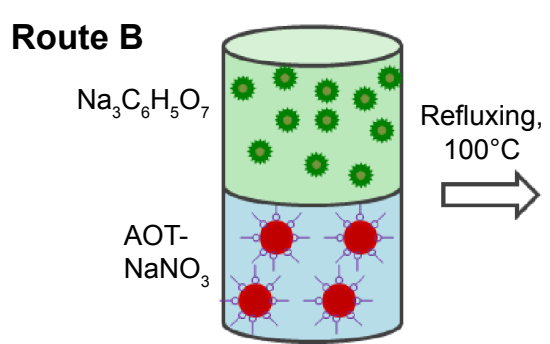

(i)

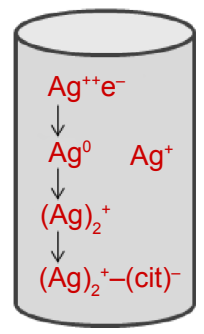

(ii)

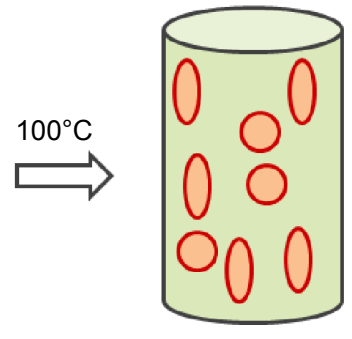

(iii)

Figure SI Schematic representation of synthesis of Ag nanoparticles and nanorods. Abbreviation: AOT, aerosol-OT.

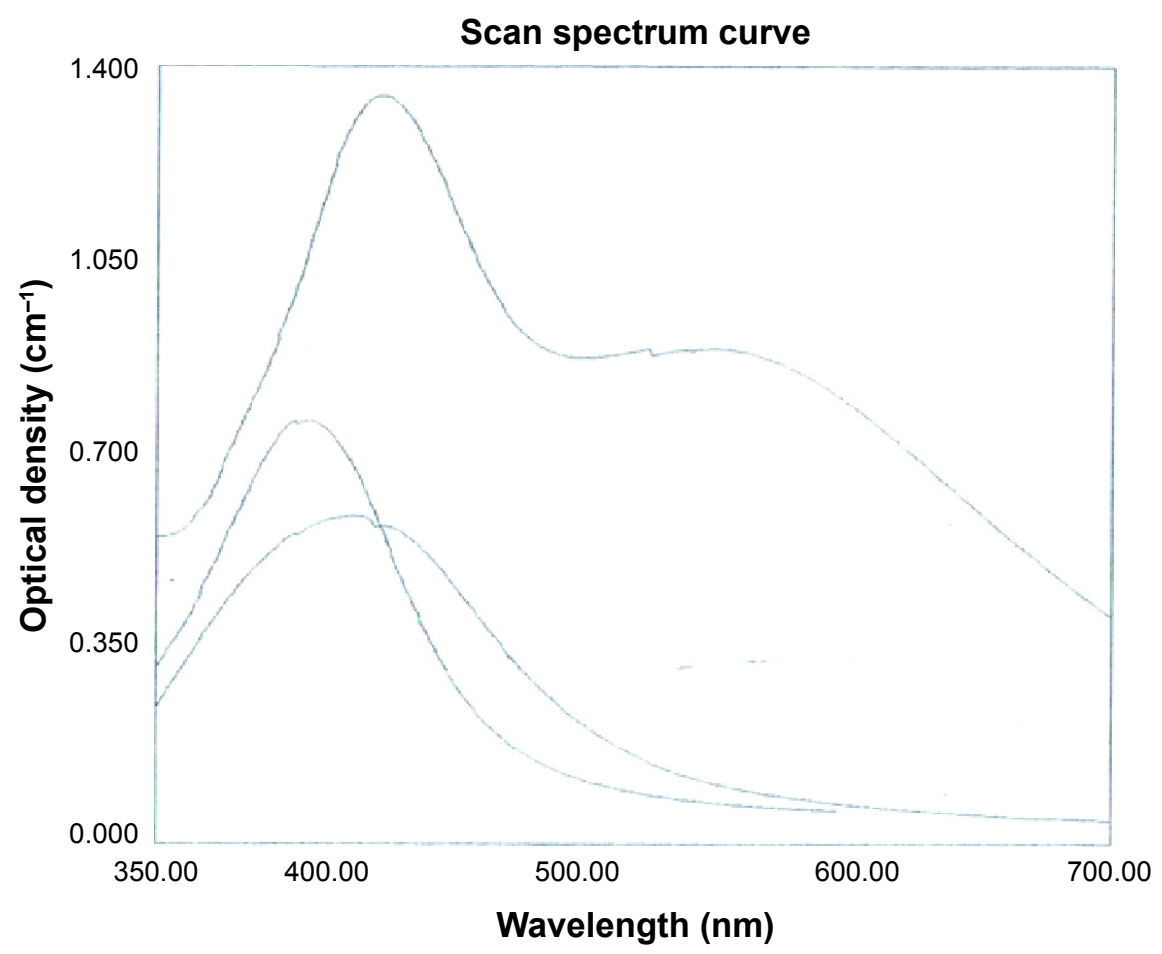

Figure S2 UV-vis spectra showing absorption at $406 \mathrm{~nm}$ and $425 \mathrm{~nm}$ for $20 \mathrm{~nm}$ and $50 \mathrm{~nm}$ spherical-shaped Ag NPs, respectively, and silver nanorods showed two plasma bands at $531 \mathrm{~nm}$ and $432 \mathrm{~nm}$.

Abbreviation: NPs, nanoparticles. 


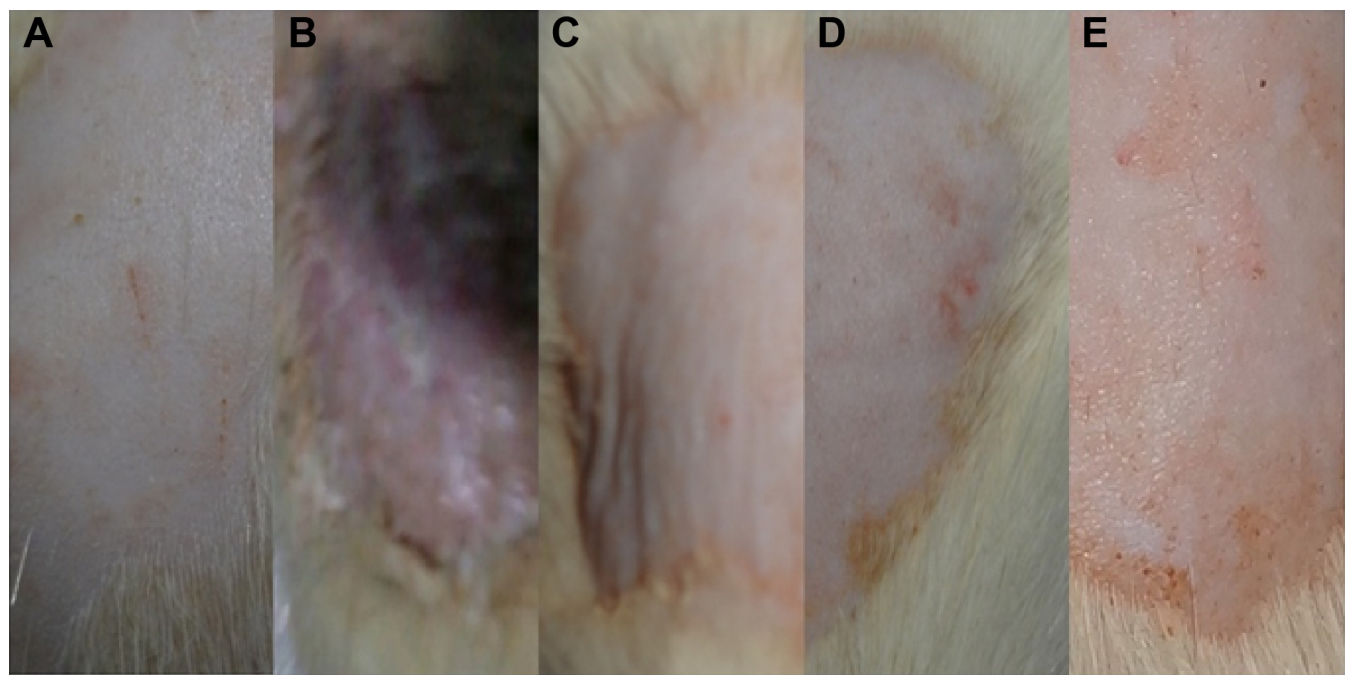

Figure S3 Comparison of ZOI for different antifungal agents in groups of studied rats (A-E)

Notes: (A) Control; (B) aqueous solution of formalin (7\%) (irritant); (C) $50 \mathrm{~nm}$ rod shaped Ag NPs; (D) $50 \mathrm{~nm}$ spherical shaped Ag NPs; (E) $20 \mathrm{~nm}$ spherical shaped Ag NPs.

Abbreviation: ZOI, zones of inhibition.
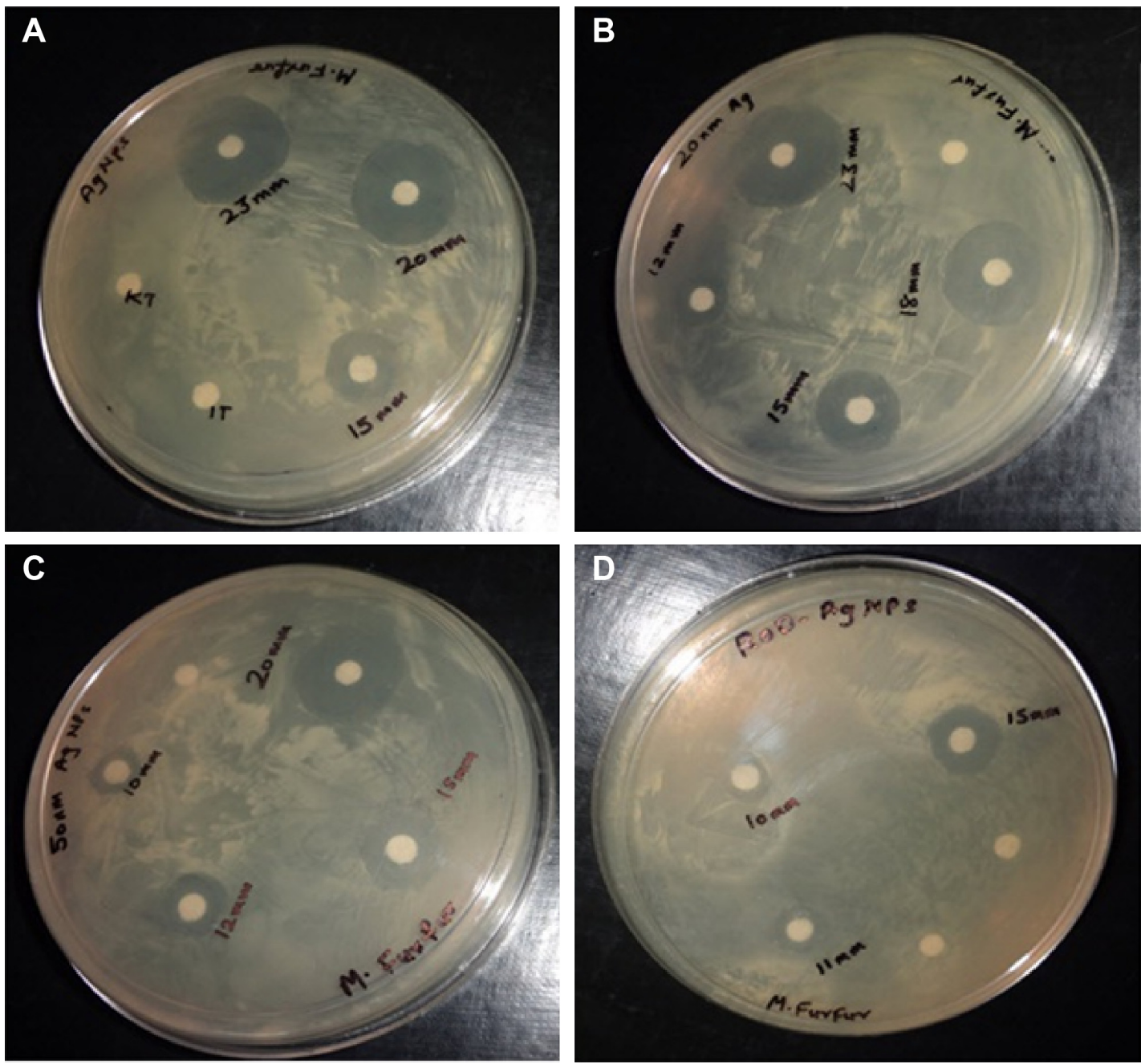

Figure S4 Skin photographs showing irritation studies.

Notes: (A) Comparative ZOI study of Ag Nps with itraconazole; (B) ZOI study of $20 \mathrm{~nm}$ spherical $\mathrm{Ag} \mathrm{Nps;} \mathrm{(C)} \mathrm{ZOI} \mathrm{study} \mathrm{of} 50 \mathrm{~nm}$ spherical Ag Nps; (D) ZOI study of

$50 \mathrm{~nm} \operatorname{rod} \mathrm{Ag} \mathrm{Nps}$

Abbreviations: NPs, nanoparticles; ZOI, zones of inhibition. 


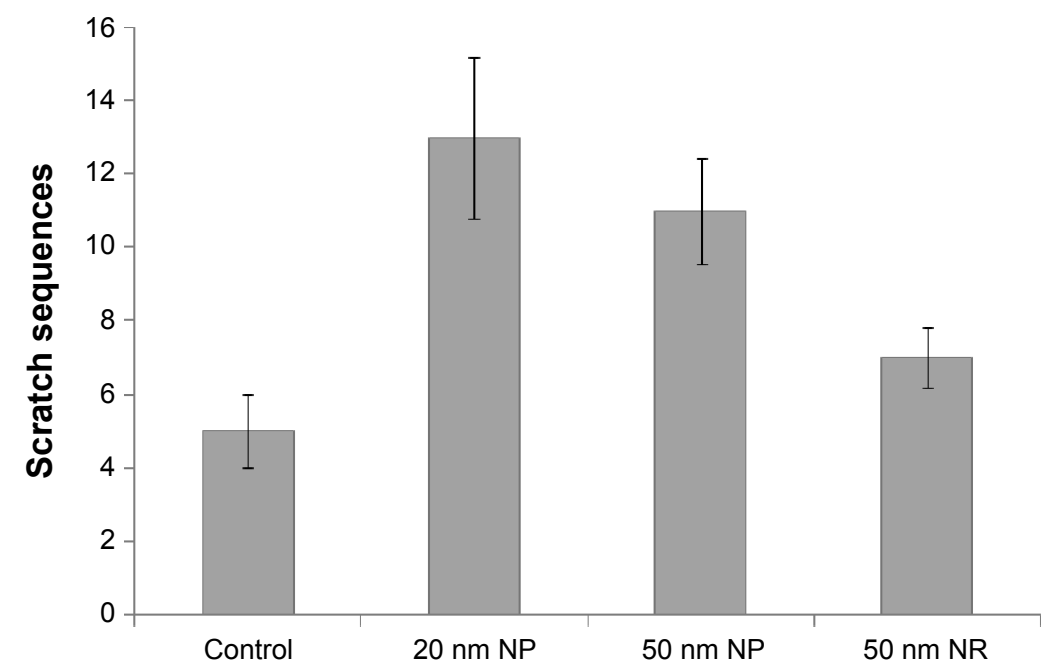

Figure S5 The graph showing scratching behavior assessment of rat for scratching tendency and comparison with control untreated rats. Abbreviations: NP, nanoparticle; NR, nanorod.

\section{Publish your work in this journal}

The International Journal of Nanomedicine is an international, peerreviewed journal focusing on the application of nanotechnology in diagnostics, therapeutics, and drug delivery systems throughout the biomedical field. This journal is indexed on PubMed Central, MedLine, CAS, SciSearch ${ }^{\circledR}$, Current Contents ${ }^{\circledR} /$ Clinical Medicine,
Journal Citation Reports/Science Edition, EMBase, Scopus and the Elsevier Bibliographic databases. The manuscript management system is completely online and includes a very quick and fair peer-review system, which is all easy to use. Visit http://www.dovepress.com/ testimonials.php to read real quotes from published authors. 